The work reported here was aided in part by funds from a Rockefeller grant to the Zoological Laboratory. We should like to express our sincere thanks to Prof L. V. Heilbrunn for his advice and encouragement, and to Dr. Merkel H. Jacobs and Dr. Paul G. LeFevre for reading the manuscript.

Clifford V. Harding Cari Feldherr

Division of Biology,

Zoological Laboratory,

University of Pennsylvania, Philadelphia.

$$
\text { July } 1 .
$$

${ }^{1}$ Callan, H. G., Hereditas, 35, Supp. 547 (1949).

${ }^{2}$ Goldstein, L., and Harding, C. V., Fed. Proc., 9, 48 (1950).

${ }^{3}$ Creeth, J. M., Biochem. J., 51, 10 (1952).

${ }^{4}$ Coons, A. H., LeDuc, E. H., and Kaplan, M. H., J. Exp. Med., 93, 173 (1951)

'Anderson, N. G., Science, 117, 517 (1953)

6 Stern, H., and Mirsky, A. E., J. Gen. Physiol., 37, 177 (1953).

\section{Kinetics of Muscular Contraction in Heavy Water}

VARIoUs lines of evidence, for example, involvement of sulphydryl groups and adenosine triphosphatase, suggest that the rate-limiting process for muscular contraction may be proton transfer. In this event, one would expect the rate of either isometric or isotonic contraction to be slowed up in the presence of heavy water $\left(\mathrm{D}_{2} \mathrm{O}\right)$. According to a recent analysis 1 , which of the two most affected will depend on whether activation or production of tension is involved.

Fig. 1 shows the development of isometric tension in normal and heavy water-Ringer solution after $20 \mathrm{~min}$. equilibration. The reduction in rate of just over three times is completely reversible. Maximum tension and relaxation phase were not altered action potentials in another muscle (frog sartorius) were found to be normal. These results, with the exception of 30 per cent less tension, are reproduced by normal Ringer solution with osmotic pressure increased by addition of sucrose to $1 \cdot 6$ times (that is, 0.416 osmolar)

Fig. 2 shows force-velocity curves for the three cases. The isotonic rate is reduced some twelve times in heavy water - Ringer solution, while for sucrose Ringer the factor is again only three.

From this we should conclude that the reaction affected is tension production, and from the magni-

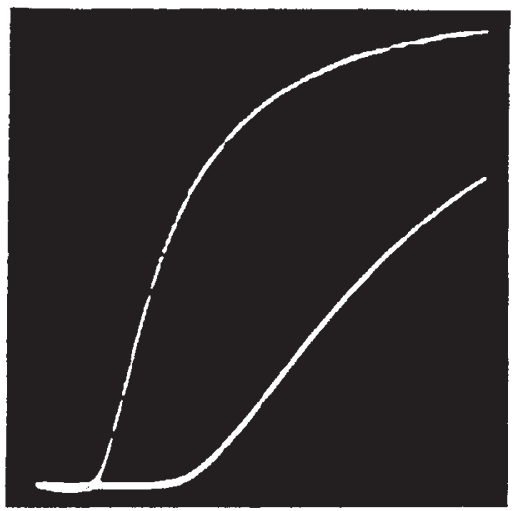

Fig. 1. Development of isometric tension in turtle (Chrysemys picta) retractor penis muscle at $0^{\circ}$ C. Left to right, in normal and heavy water - Ringer solution

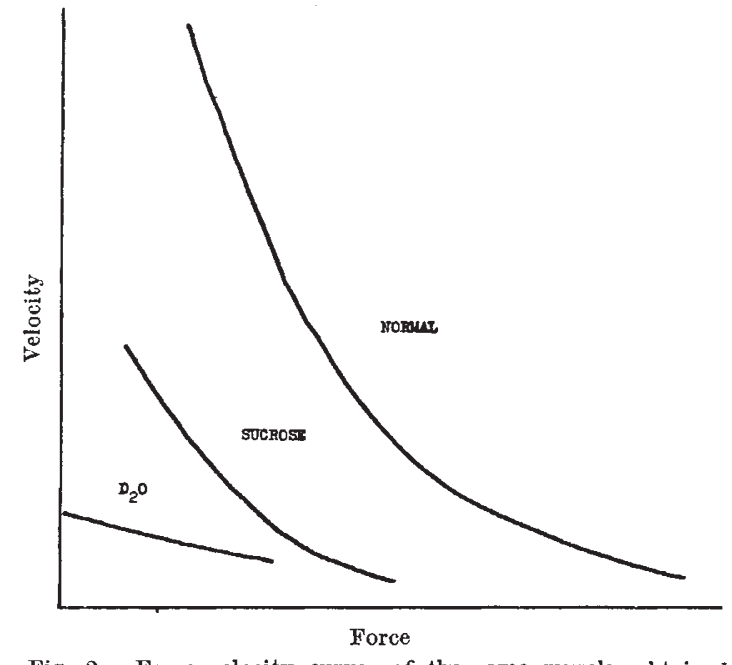
Fig. 2. Force-velocity curves of the same muscle, obtained
with a continuously recording device

tude of the effect more than one (possibly three) protons are involved.

I am indebted to Dr. N. Geschwind for observation of action potentials by micro-electrode technique, and to the Muscular Dystrophy Associations of America for support.

Biology Department,

M. C. Goonall

Massachusetts Institute of Technology,

Cambridge, Mass.

May 23.

${ }^{1}$ Goodall, M. C., Yale J. Biol. Med., 30, 224 (1957).

\section{Influence of Water Deprivation on Taste Sensitivity in Man}

IN a previous communication ${ }^{1}$, I presented results showing that forced loss of salt from the body is accompanied by increases in taste sensitivity to 'salt' in human subjects. Sensitivity to 'sweet', 'sour' and 'bitter' remained unchanged. In a study of the preference behaviour of thirsty (deprived of water for $17 \frac{1}{2}-19 \mathrm{hr}$.) and non-thirsty rats, Young and Falk ${ }^{2}$ report that thirsty rats reject hypertonic solutions and tend to prefer water to hypotonic salt solutions. Thus it appears that the preference behaviour of rats deprived of water is practically the opposite of that shown by rats deficient in salt. In view of the finding that salt deficiency is accompanied by an increase in sensitivity to salt, Young and Falk's results suggest that water deprivation may be accompanied by a decrease in sensitivity to salt.

To check this, four human subjects $(H, R, J$ and $C)$ were rendered water-deficient and their sensitivity to 'salt' (sodium chloride) and 'sour' (sulphuric acid) was studied. Details of the procedure used to establish absolute thresholds were reported previously ${ }^{1}$. After rinsing the mouth, subjects were careful to spit, out as much as possible of the fluid before swallowing. Nevertheless, very small amounts of fluid were undoubtedly swallowed during testing.

Throughout the control, experimental and recovery periods of the experiment (nine days for subjects $H$ and $R$ and eight days for subjects $J$ and $C$ ) the overall caloric value of the food intake of all subjects was controlled. It averaged about 2,100 cal./day for $H$, about 2,650 cal./day for $R$, about $2,840 \mathrm{oal}$./day 